\title{
EFFECT OF FLASH GAS BYPASS ON PERFORMANCE OF VCR SYSTEM
}

\author{
D.D. Bhoge ${ }^{1}$, A.M.Patil ${ }^{2}$ \\ ${ }^{I} P G$ Student PVPIT, Budhgaon, Sangli \\ ${ }^{2}$ Vice Principal of PVPIT, Budhgaon, Sangli
}

\begin{abstract}
In this paper performance of vapor compression refrigeration system (VCRS) with R134a in direct expansion (DX) mode and flash gas bypass (FGB) mode are compared. The performance of system can be improved in FGB mode. When system is operated at same operating conditions, in DX and FGB mode, then it is observed that COP increases from $2 \%$ to $7 \%$ in FGB mode and cooling effect at low load is $2 \%$ to $16 \%$ more. Discharge temp in case of FGB mode is less than DX mode. Also pressure drop across evaporator is less in FGB mode. In DX mode vapor does not participate in cooling effect but it will create pressure drop across evaporator and because of it compressor work increases. In FGB mode vapors are bypassed because of it less pressure drop is created across evaporator and less compressor work.
\end{abstract}

Keywords: Flash gas bypass, direct expansion and VCRS etc...

\section{INTRODUCTION}

Improving the efficiency of vapor compression refrigeration system is important for its application. One possible method is flash gas bypass (FGB) which was described by Stefan Elbel et al. [4] and by Niraj Agrawal et al. [5].

In current research, flash gas bypass system is used. Flash chamber is developed for separating [7] the flash gas formed during expansion process. Bypassed gas is directly send to the compressor and only liquid is send to the evaporator. The main advantage of it is that to reduce pressure drop in evaporator and to improve the refrigerant distribution. Also cooling effect is increased due to improved refrigerant distribution [4] and compressor work reduced due to reduced pressure drop across evaporator.

This Paper presents the results of experimentation performed on refrigeration system in direct expansion mode and flash gas bypass mode with R134a. The experimental results of the flash gas bypass system are directly compared with conventional system with direct expansion.

\section{FLASH GAS CONCEPT}

In a conventional vapor compression system with direct expansion $(D X)$, refrigerant under high pressure is expanded to a lower pressure before it enters the evaporator. The refrigerant state at the outlet of the expansion device is in a two-phase condition, provided that the fluid crosses the saturated liquid line during the isenthalpic expansion process. As a result, some fraction of the refrigerant flow enters the evaporator already in a vapor state without having a significant cooling effect. The idea behind the Flash Gas Bypass (FGB) concept is to bypass this vapor flow around the evaporator and by feeding the evaporator with liquid refrigerant, pressure drop is reduced and refrigerant distribution is improved.

Fig. 1 shows the schematic of a flash tank. A flash tank is a pressure vessel; wherein the refrigerant liquid and vapour are separated see fig. 2 and point 3 . The refrigerant from condenser is first expanded to low pressure. In the flash tank, the refrigerant liquid and vapour are separated (point 3 ). The separated liquid is fed to the evaporator (Process 54). The vapour in the flash tank is bypassed to compressor (Process 3-6) and compressed to the condenser pressure. In the absence of flash tank, the refrigerant condition at the inlet to the evaporator would have been point 3 i.e wet vapour.

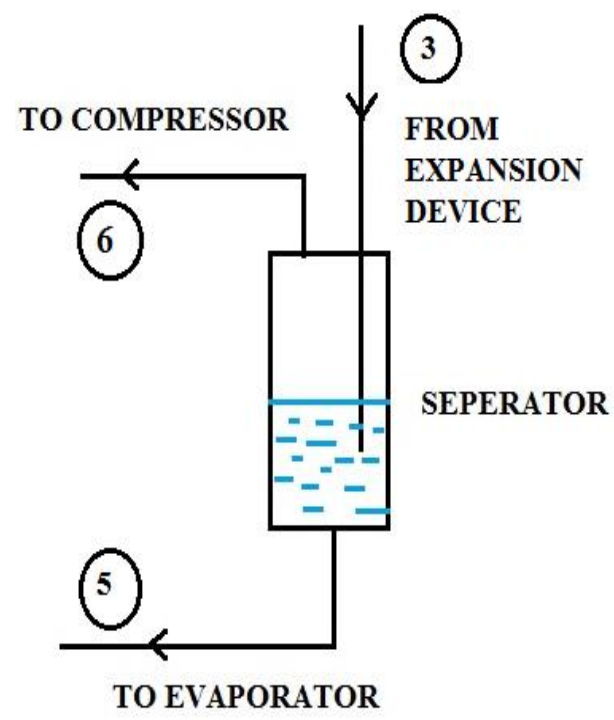

Fig-1: Line diagram of Flash Tank 


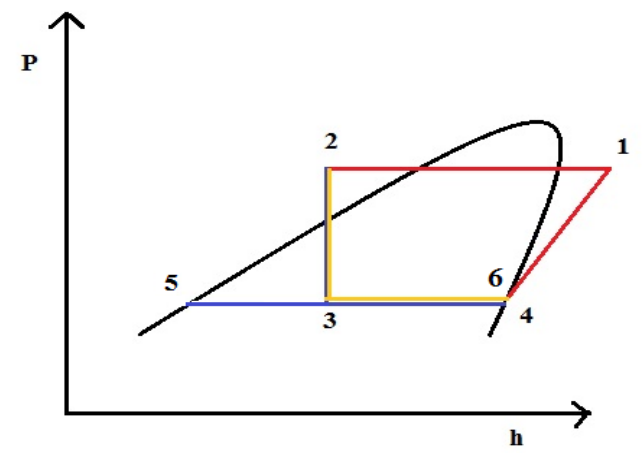

Fig -2: p-h digarm

\section{OBJECTIVE}

The prime objective of research is to compare the performance of the direct expansion (DX) system with Flash gas bypass (FGB) system with variation of the load on the system.

Accordingly standard system is designed and developed. This system operated in direct expansion as well as flash gas bypass mode with the help of 4 service valves provided.

\section{EXPERIMENTAL SET UP}

Fig. 3 shows the block diagram of experimental setup. For DX mode open the valve V2 and close the valve V1, V4 and $\mathrm{V} 3$ and for FGB mode open the valve V1, V4 and V3 and close V2. DX system is regular (Standard) system. FGB mode in which vapour formed during expansion are separated at the end of expansion process in separator at point 3 . After point 3 only liquid is sent to the evaporator and vapors to the compressor inlet.

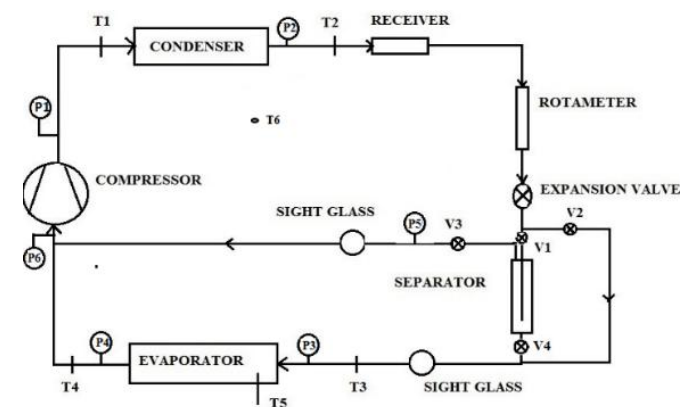

Fig-:3 Line diagram for VCR System with DX and FGB

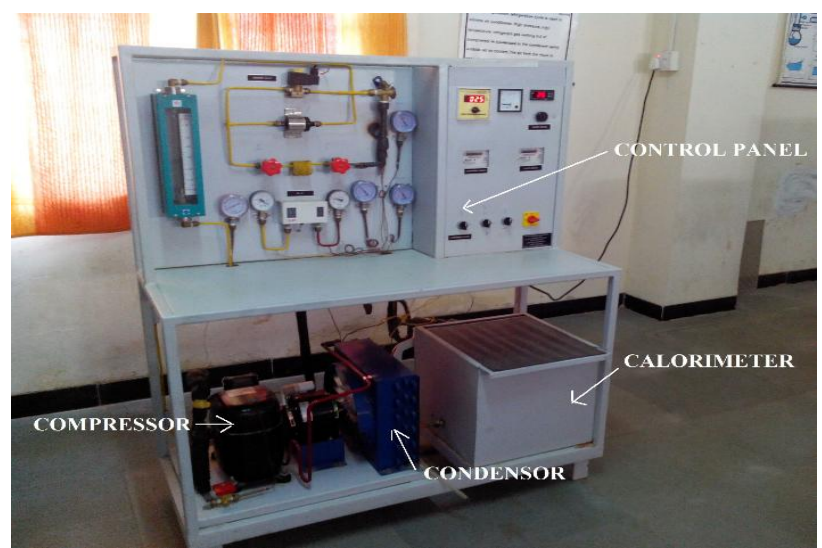

Photo-1: Experimental Set up

\section{RESULTS AND DISCUSSION}

To check performance of the set up number of readings are taken by using control panel. By varying the load on evaporator readings are taken.

Table-1: Variation of system load

\begin{tabular}{|l|l|}
\hline Sr. No. & Load in $\mathbf{k W}$ \\
\hline 1 & 0.9 \\
\hline 2 & 1.0 \\
\hline 3 & 1.1 \\
\hline 4 & 1.7 \\
\hline 5 & 1.9 \\
\hline 6 & 2.4 \\
\hline
\end{tabular}

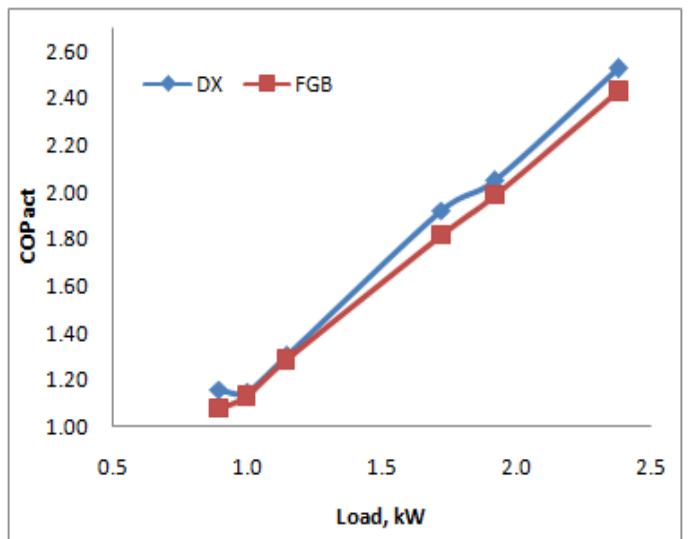

Chart-1: Comparison of actual COP in DX and FGB mode

Above chart no. 1 shows that as the load on the evaporator increases the COP also increases. COP in FGB mode is more. Rise in actual COP in FGB mode is observed from $1.27 \%$ to $7.28 \%$ for the load change from $0.9 \mathrm{~kW}$ to $2.4 \mathrm{~kW}$.

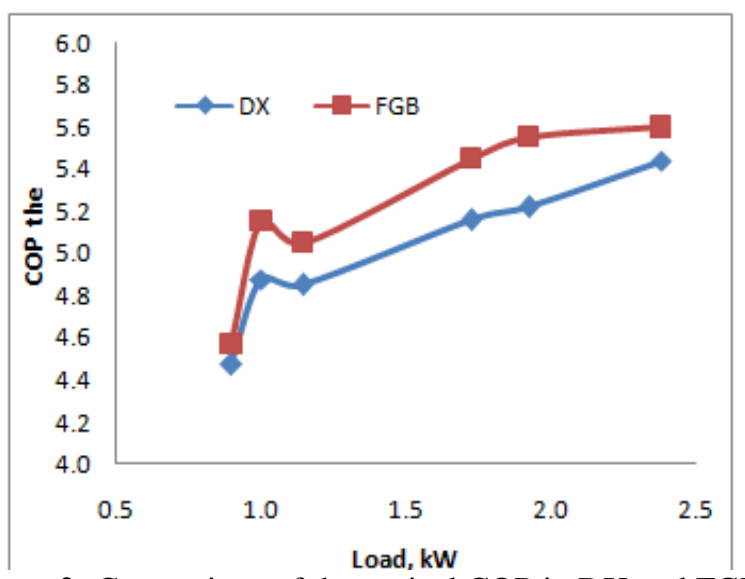

Chart-2: Comparison of theoretical COP in DX and FGB mode

Above chart no. 2 shows that as the load on the evaporator increases the COPth in DX and FGB mode also increases. And COP in FGB mode is more than DX mode. Increase in theoretical COP in FGB mode is observed from $2 \%$ to $5.93 \%$ for the load change from $0.9 \mathrm{~kW}$ to $2.4 \mathrm{~kW}$. 


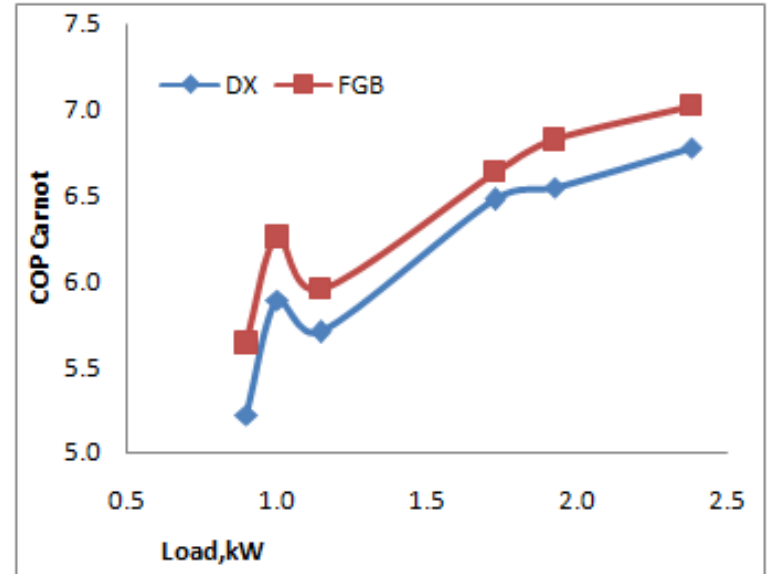

Chart-3: Comparison of Carnot COP in DX and FGB mode

Above chart no. 3 shows that as the load on the evaporator increases the COP Carnot in DX and FGB mode also increases. And COP in FGB mode is more than DX mode. Increase in theoretical COP in FGB mode is observed from $2.38 \%$ to $7.42 \%$ for the load change from $0.9 \mathrm{~kW}$ to $2.4 \mathrm{~kW}$.

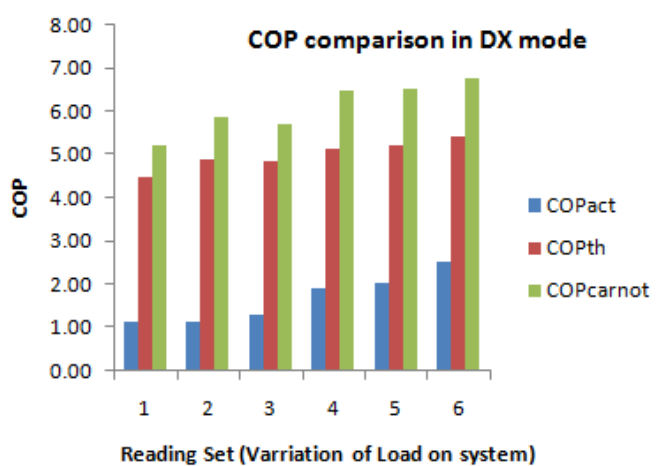

Chart-4: Comparison of actual, theoretical and Carnot COP in DX mode

Above chart no.4 shows the comparison of COP actual, COPth and COP Carnot in DX mode. COP Carnot is greater than COP actual and COPth. COP actual varies from 1.07 to 2.43, COP theoretical varies from 4.47 to 5.44 and COP Carnot varies from 5.22 to 6.78 . It is because of losses through walls of calorimeter chamber etc.

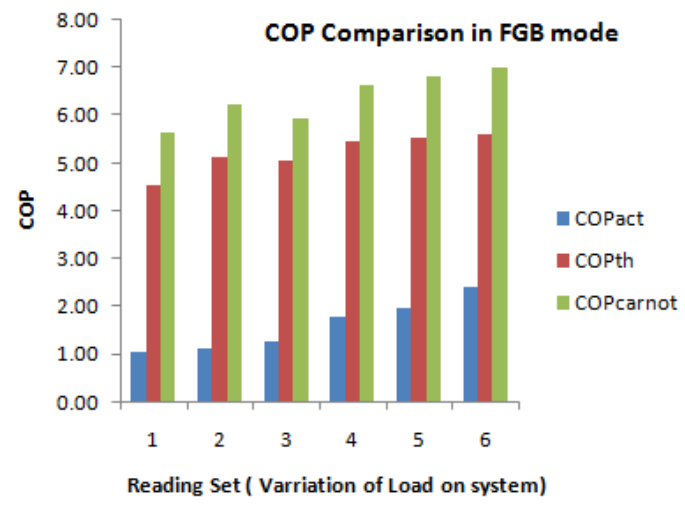

Chart-5: Comparison of actual, theoretical and Carnot COP in FGB mode
Above chart no.5 shows the comparison of COP actual, COPth and COP Carnot in FGB mode. COP Carnot is greater than $\mathrm{COP}$ actual and COPth. COP actual varies from 1.15 to 2.52 , COP theoretical varies from 4.57 to 5.60 and COP Carnot varies from 5.64 to 7.03. It is because of losses through walls of calorimeter chamber etc.

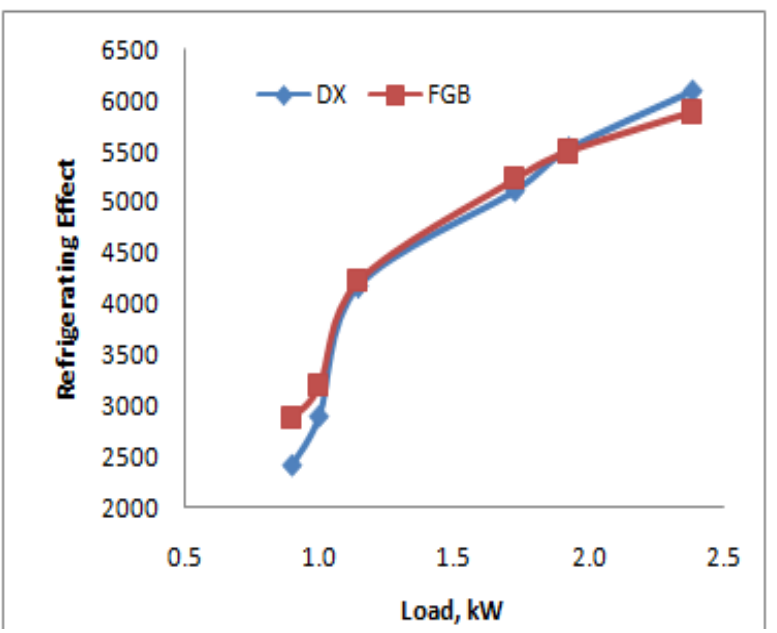

Chart-6: Comparison of refrigerating effect in DX and FGB mode

Above chart no. 6 shows the comparison of refrigerating effect in DX and FGB mode. Refrigerating effect in FGB mode is more as compared to DX mode. It is because of flash gas bypass. Only liquid sent to the evaporator. Because of it heat transfer coefficient increases and refrigerating effect. At lower load refrigerating effect is about $16 \%$ more but as load increase refrigerating effect decreases.

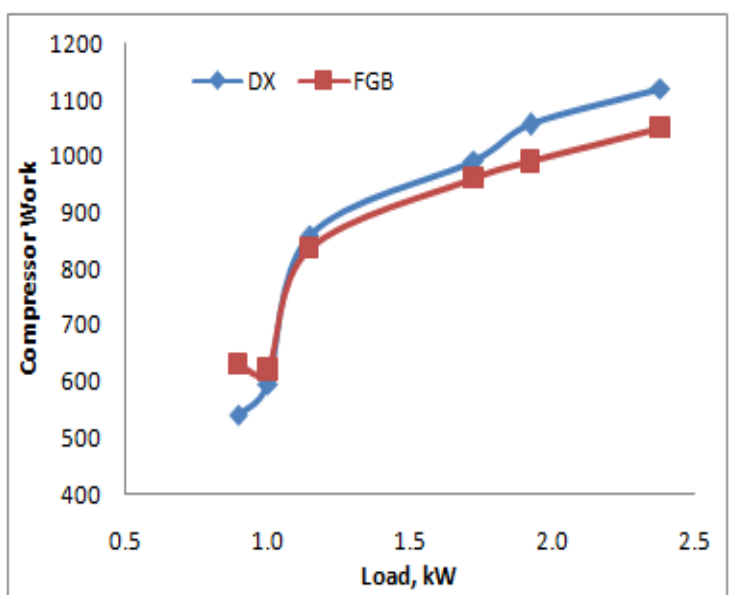

Chart-7: Comparison of compressor work in DX and FGB mode

Above chart no.7 shows the comparison of compressor work in DX and FGB mode. Compressor work is more in case of DX mode. It because of more pressure drop across evaporator is more in case of DX mode so more compressor work required. At higher load upto $6.67 \%$ more work required. 


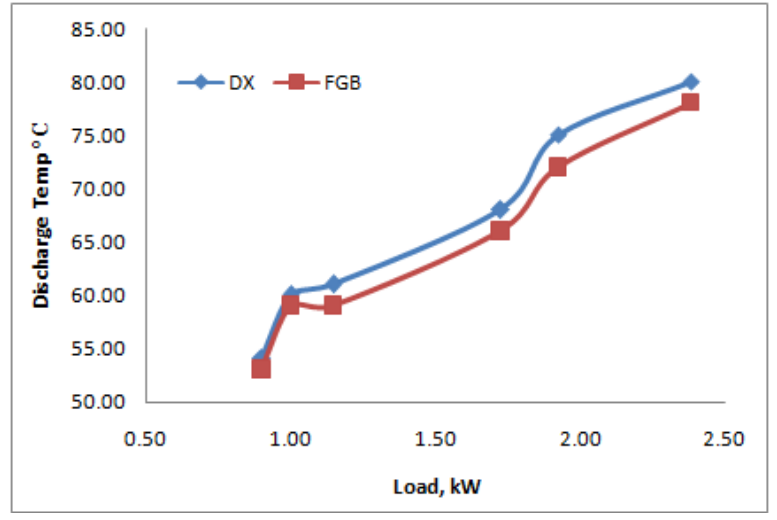

Chart-8: Comparison of discharge temp in DX and FGB mode

Above chart no. 8 shows the comparison of discharge temp in DX and FGB mode. Discharge temp is more in case of DX mode. It because of superheat at evaporator outlet and more pressure drop across evaporator.

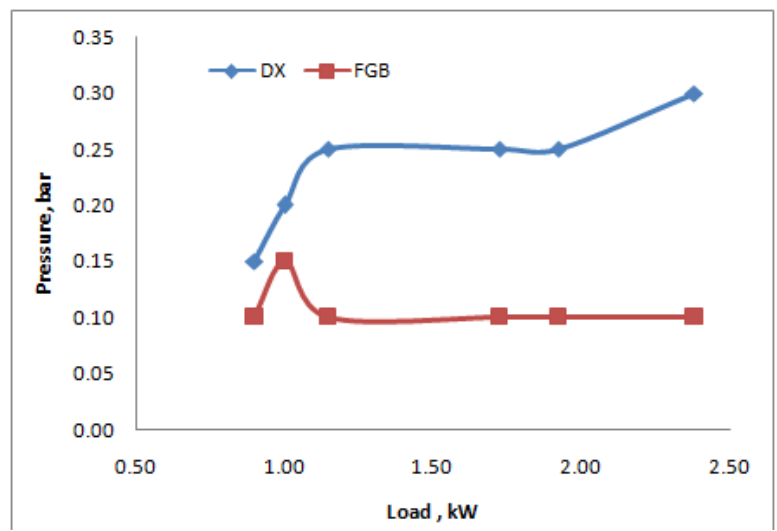

Chart-9: Comparison of pressure drop across evaporator in DX and FGB mode

Above chart no.9 shows the comparison of pressure drop across evaporator in DX and FGB mode. Pressure drop is more in case of DX mode. It because of wet refrigerant entering is in evaporator in case of DX mode. And in case of FGB mode only liquid is sent to evaporator.

\section{CONCLUSIONS}

Following conclusion are made from the work carried out on effect of flash gas bypass on VCR system.

When system is operated at same loading conditions in FGB and DX mode, the actual COP in FGB mode increased about $1.27 \%$ to $7.28 \%$, theoretical COP about $2.07 \%$ to $5.93 \%$ and Carnot COP $2.38 \%$ to $7.42 \%$ over DX mode.

The main reason for the improved performance of this system in FGB mode is due to only liquid refrigerant sent the evaporator. Liquid has more heat transfer coefficient as that of vapor. Refrigerant effect also improved about $2 \%$ to $16 \%$.

Because of Flash Gas bypass it is observed that less pressure drop in evaporator about 0.1 bar. Due to less pressure drop compressor work is reduced to $9 \%$. And discharge temp reduced $2^{\circ} \mathrm{C}$ to $4^{\circ} \mathrm{C}$.

\section{ACKNOWLEDGEMENTS}

The work presented in this paper was funded by the N. K. ORCHID College of Engineering and Technology Solapur. The authors would like to thank the NKOCET Solapur for their sponsorship.

\section{REFERENCES}

[1]. Beaver, A.C., Yin, J., Bullard, C.W., Hrnjak, P.S., 1999. "An Experimental Investigation of Transcritical Carbon dioxide Systems for Residential Air-Conditioning". ACRC Report CR-18. University of Illinois at Urbana-Champaign [2]. Pega S. Hrnjak *, Mark A. Shannon, Todd M. Leicht, Norman R. Miller, "Detection of liquid mass fraction at the evaporator exit of refrigeration systems", Int. J. Therm. Sci. (2001) 40, 773-786

[3]. Thomas H. Herbert, "Flash gas and superheat eliminator for evaporator and method therefor", United States Patent2002, Patent No. US 6,460,358 B1,

[4]. Stefan Elbel, Pega Hrnjak, "Flash gas bypass for improving the performance of transcritical R744 systems that use microchannel evaporators, International Journal of Refrigeration",Vol. 27 (2004) 724-735

[5]. Neeraj Agrawal, Souvik Bhattacharyya, "Studies on a two-stage transcritical carbon dioxide heat pump cycle with flash intercooling", Applied Thermal Engineering, Vol. 27 (2007) 299- 305

[6]. Chad D. Bowers, Predrag S. Hrnjak, "Developing two phase R134a flow after an expansion valve in $8.7 \mathrm{~mm}$ tube", International Refrigeration and Air Conditioning Conference.(2008) 2398 page 1.

[7]. Nooki Shikazono. Ryuhei Azuma, "Development of compact gas-liquid separator using surface tension", International Symposium on Next-generation Air Conditioning and Refrigeration Technology, 2010, Tokyo, Japan

[8]. Hanfei Tuo, Pega Hrnjak, "Flash gas bypass in mobile air conditioning system with R134a, International Journal of Refrigeration”, Vol. 35 (2012) I869 - I877

[9]. Kale S. S., Patil A. M.“ Experimental investigation of Multi-evaporator system” (2012) Dissertation report PVPIT Budhgaon.

\section{Books}

[1]. Roy J. Dossat, Principles of Refrigeration, Fourth Edition, Pearson Publication.

[2]. 'Refrigeration and Air conditioning' by Manohar Prasad, New Age International Publication.

[3]. American Society Heating Refrigeration and Air Conditioning. ASHRAE Hand Book. 2005

[4]. Arora, C.P. Refrigeration and Air Conditioning. Second edition. Tata McGraw-Hill Publishing Company Ltd. 2000.

[5]. W.F. Stocker, Refrigeration and Air Conditioning. Second edition. Tata McGraw-Hill 